Provided for non-commercial research and education use. Not for reproduction, distribution or commercial use.

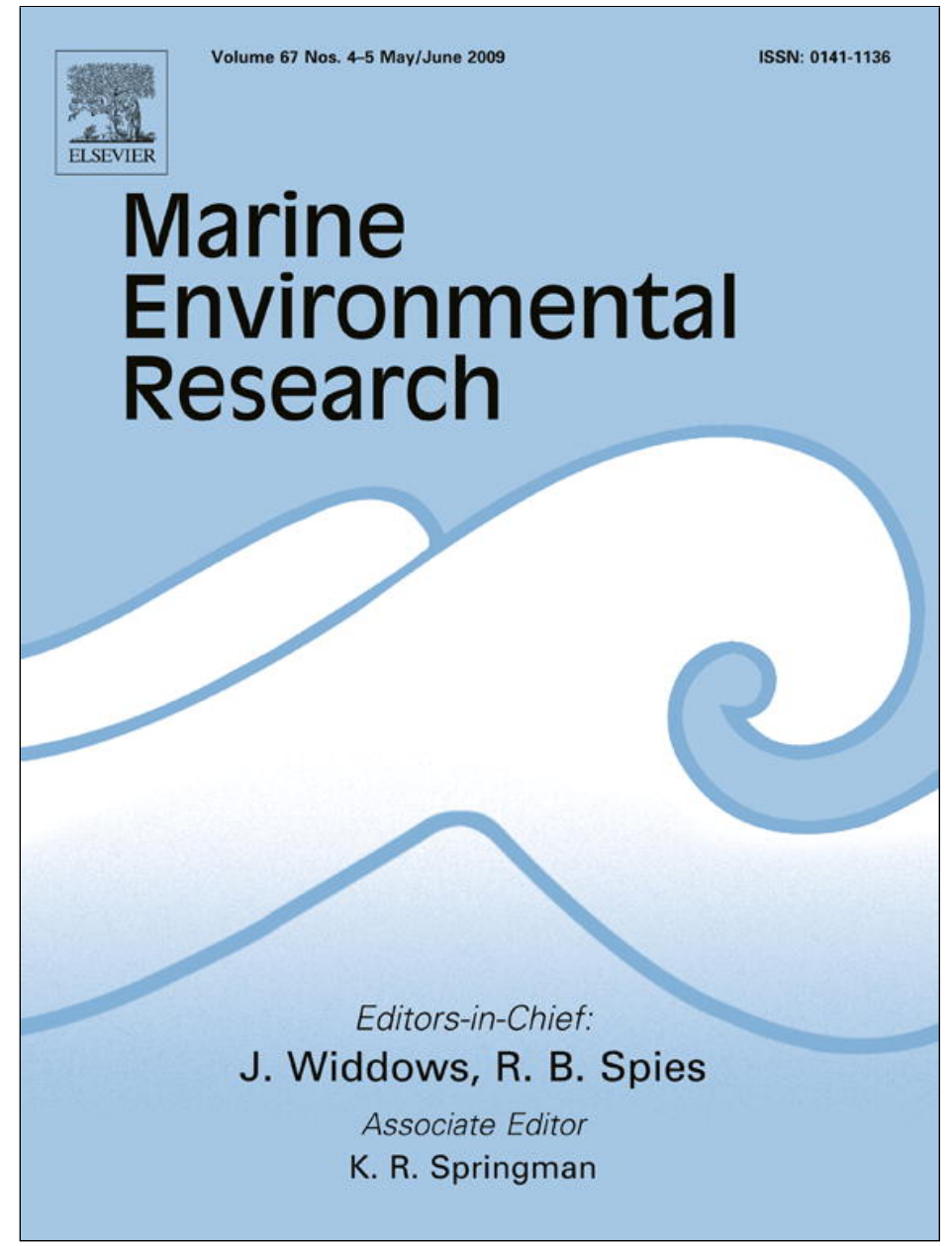

This article appeared in a journal published by Elsevier. The attached copy is furnished to the author for internal non-commercial research and education use, including for instruction at the authors institution and sharing with colleagues.

Other uses, including reproduction and distribution, or selling or licensing copies, or posting to personal, institutional or third party websites are prohibited.

In most cases authors are permitted to post their version of the article (e.g. in Word or Tex form) to their personal website or institutional repository. Authors requiring further information regarding Elsevier's archiving and manuscript policies are encouraged to visit:

http://www.elsevier.com/copyright 


\title{
Influence of a breakwater on nearby rocky intertidal community structure
}

\author{
Gustavo M. Martins ${ }^{\mathrm{a}, \mathrm{b}, \mathrm{c}, *}$, André F. Amaral ${ }^{\mathrm{a}}$, Francisco M. Wallenstein ${ }^{\mathrm{a}, \mathrm{c}, \mathrm{d}}$, Ana I. Neto ${ }^{\mathrm{a}, \mathrm{c}}$ \\ ${ }^{a}$ Secção Biologia Marinha, Departamento de Biologia, Universidade dos Açores, 9501-801 Ponta Delgada, Açores, Portugal \\ ${ }^{\mathrm{b}}$ Marine Biology and Ecology Research Centre, Marine Institute, University of Plymouth, Plymouth PL4 8AA, UK \\ ' CIIMAR, Centro Interdisciplinar de Investigação Marinha e Ambiental, Rua dos Bragas 289, 4050-123 Porto, Portugal \\ ${ }^{\mathrm{d}}$ Heriot-Watt University, School of Life Sciences, John Muir Building, Edinburgh EH14 4AS, UK
}

\section{A R T I C L E I N F O}

\section{Article history:}

Received 25 November 2008

Received in revised form 27 February 2009

Accepted 2 March 2009

\section{Keywords:}

Sea defence structure

Environmental impact

Benthic assemblages

Wave-exposure

Recruitment

ACI (After-Control-Impact) design

\begin{abstract}
A B S T R A C T
It is widely recognised that coastal-defence structures generally affect the structure of the assemblages they support, yet their impact on adjacent systems has been largely ignored. Breakwaters modify the nearby physical environment (e.g. wave action) suggesting a local impact on biological parameters. In the present study, an ACI (After-Control-Impact) design was used to test the general hypothesis that the artificial sheltering of an exposed coast has a strong effect on the structure and functioning of adjacent systems. The effects of a reduction in hydrodynamics were clear for a number of taxa and included the replacement of barnacles, limpets and frondose algae by an increasing cover of ephemeral algae. These effects were evident both at early and late successional stages. Results suggest that the artificial sheltering of naturally exposed coasts can have a strong impact promoting a shift from consumer- to producer-dominated communities, which has important ecological and energetic consequences for the ecosystem.
\end{abstract}

(c) 2009 Elsevier Ltd. All rights reserved.

\section{Introduction}

Since the 1960s there has been an unprecedented rate of habitat loss, modification or degradation with some European countries reporting reductions over $50 \%$ of the original coastal habitat (Airoldi and Beck, 2007). Coastal urbanisation including the replacement of natural substrata by artificial ones or the deployment of artificial structures to protect the flooding of low-lying lands and to prevent coastal erosion is likely to increase in the next decades due to sea-level rise or increased storm frequency (Thompson et al., 2002). There is an increasing awareness that coastal urbanisation leads to important changes in the structure and functioning of marine ecosystems including the loss of keystone taxa and associated reductions of local diversity (e.g. Benedetti-Cecchi et al., 2001; Mangialajo et al., 2008). Although similarities exist between assemblages on natural and built reefs, patterns of species distribution are generally modified in the latter (Bulleri et al., 2004; Bulleri and Chapman, 2004) and the assemblages are characterised by a reduced subset of species that commonly occur on natural shores (e.g. Chapman, 2003; Chapman and Bulleri, 2003). Patterns of species recruitment to seawalls also tend to differ from that on natural shores (Bulleri, 2005). In addition, artificial structures can also

\footnotetext{
* Corresponding author. Address: Marine Biology and Ecology Research Centre, Marine Institute, University of Plymouth, Plymouth PL4 8AA, UK. Tel.: +351 296650 000; fax: +351296650100.

E-mail address: gustavo.martins@plymouth.ac.uk (G.M. Martins).
}

facilitate the colonisation and spread of non-indigenous species (Bulleri and Airoldi, 2005; Glasby et al., 2007), acting as stepping-stones. Thus, sea defence structures seem to act as functional different habitats.

The above mentioned studies have generally compared the assemblage structure on artificial and natural shores while little is known on how these structures affect the structure of adjacent rocky intertidal communities (but see Goodsell et al., 2007). Work done on other systems including mangrove forests (Kelaher et al., 1998), fish assemblages (Clynick et al., 2008) and soft-sediment habitats (see Bertasi et al., 2007 and references therein) has shown that the influence of artificial structures can extend well beyond the very communities they support.

Breakwaters are deployed for reducing wave action and preventing coastal erosion. Breakwaters also modify near-shore water circulation (Zyserman et al., 2005) and sediment transport (Thomalla and Vincent, 2003; Cuadrado et al., 2005). Changes in the physical environment produced by the deployment of breakwaters will likely affect the structure of assemblages under their influence. For instance, wave action conditions have recurrently been shown to affect the distribution and abundance of intertidal organisms (e.g. Underwood and Jernakoff, 1984), organism settlement (e.g. Abelson and Denny, 1997), mortality (e.g. McQuaid and Lindsay, 2000), and biological interactions (e.g. Jonsson et al., 2006). Sedimentation has also been shown to influence rocky intertidal community structure of intertidal assemblages (reviewed by Airoldi, 2003). Specifically, sedimentation increases 
disturbance leading to a reduction in the vertical structure of algal assemblages and thus the replacement of frondose by turf-forming algae (Airoldi, 1998). In addition, sedimentation interferes with grazing gastropod activities and thus reducing their abundance (Airoldi and Hawkins, 2007).

In the present study, we compared the rocky intertidal structure of assemblages sheltered by an existing breakwater to that of control areas. Specific hypothesis were that the increased sediment deposition in the area sheltered by the breakwater will lead to a reduction in the abundance of frondose algae promoting the proliferation of turf-forming species lower on the shore and a reduction in the abundance of grazing gastropods upper on the shore. Chthamalus stellatus, a barnacle which dominates on wave-exposed shores (Jenkins, 2005) is predicted to decrease in cover in response to the reduction in wave action and to abrasion by the increased sedimentation in the sheltered area. In addition, changes in the water-circulation caused by the presence of the breakwater are hypothesised to affect macroalgae and/or invertebrate recruitment (Abelson and Denny, 1997). However, and except for the recruitment of C. stellatus, there is no directional hypothesis as to how early successional assemblages will differ between the impacted and control locations.

\section{Materials and methods}

\subsection{Study site and community}

The present study was done on a moderate to highly exposed rocky platform on the south coast of Pico, Azores (Fig. 1). Unlike most shores on the remainder of the Azores archipelago, Lajes do Pico is a large and gentle sloping reef with a variety of habitats (Morton et al., 1998) that support a diverse community of plants and animals (for details on the composition and community structure of this reef see Morton et al., 1998; Ávila et al., 2005; Martins et al., 2008). The uniqueness of this area has contributed to its classification as SCI (site of community interest) and SAC (special area of conservation). The main economic activity of the small village of Lajes do Pico is agriculture and, to a smaller extent, fishing and tourism (whale-watching). Extractive activities on the coastal area include angling, crabbing and harvesting of octopus and limpets. The rocky platform is divided in two by a small lagoon in which the inner part is used as an anchorage point harbouring small fishing and recreational boats. Due to high wave action in winter, an already existing, but small, breakwater was extended $\sim 100 \mathrm{~m}$ offshore towards the north in order to protect the entrance of the lagoon. The breakwater runs parallel to the northern rock platform at approximately $50 \mathrm{~m}$ away from the shore and is made of large, regularly sized concrete blocks that rise approximately $4 \mathrm{~m}$ above seawater level. The construction resulted in the artificial sheltering of the northern area of the rocky platform, locally denominated as Lajido, previously exposed to open swell. Besides the presence of the breakwater, there are no apparent differences (e.g. geomorphology) between the northern and southern rock platforms and the impact of the small harbour is expected to be small. The study began one year following the completion of the breakwater. During the course of study, occasional construction work was done in the inner part of the lagoon close to the harbour. Although the harbour is $\sim 200 \mathrm{~m}$ away this may have led to pulse increases in sediment load. The southern platform is protected from such disturbances due to the ground elevation separating the two areas.

\subsection{Sampling design}

In order to examine the effects of the breakwater on the adjacent algal and animal assemblages, a beyond-BACI design (see Underwood, 1991, 1992, 1993, 1994 for revision) was not possible due to the lack of a priori data. However, beyond-BACI designs can be modified and applied to situations where no before data exist and have been widely used (e.g. Chapman et al., 1995; Terlizzi et al., 2005). These designs allow the determination of consistent differences between the disturbed and several control locations although it is generally not possible to attribute causation to a particular event (see Terlizzi et al., 2005; Glasby, 1997 for discussion).

In the present study, we used an asymmetrical ACI design to compare the abundance of conspicuous eulittoral taxa in a putatively disturbed location (a rocky platform artificially sheltered by a breakwater) and three control locations. All locations (the disturbed and controls) are on the same rocky platform and at least $150 \mathrm{~m}$ apart from each other. The disturbed location is located in the northern part of this platform whereas all control locations were located south to this. Although the non-interspersion of control locations introduces an issue of spatial confounding which

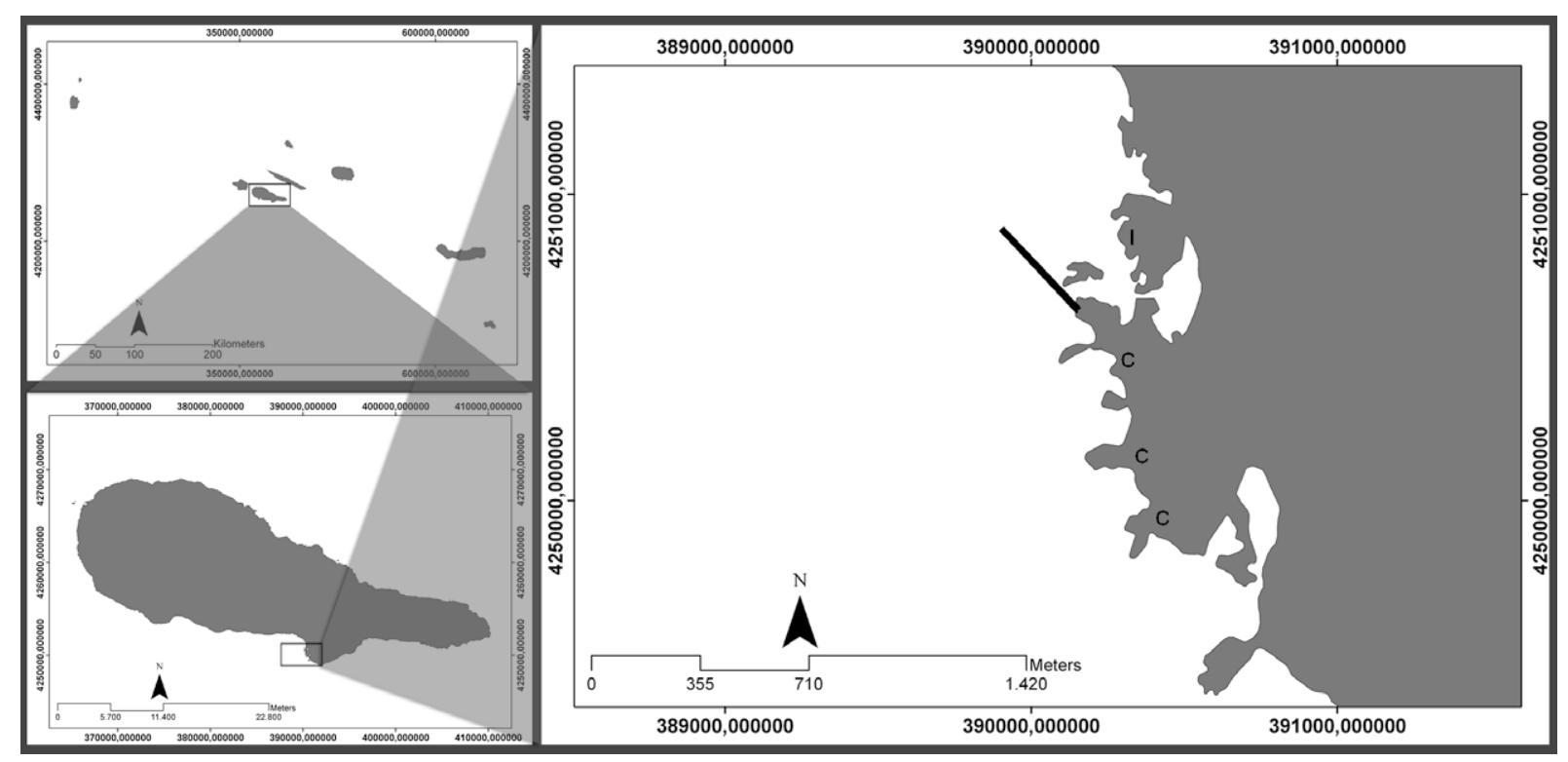

Fig. 1. Azores archipelago; Pico island; and the study area showing the built breakwater and the impacted (I) and control (C) locations used. 
may affect the interpretation of results (Underwood, 1994), this situation was compulsory as north of the disturbed location the rocky platform gives rise to a vertical wall falling directly into the water. As mentioned above, this specific rocky platform is unique on the Azorean shores, which are characterised by steep slopes. Since the slope of the shore can significantly affect the processes structuring intertidal communities (Knott et al., 2004) these were not considered appropriate controls to the disturbed location (see Underwood (1994) for the desirable characteristics that control locations must have). Analyses of spatial correlation (data not shown) showed that the abundance of organisms was only weekly correlated with the location of controls and hence suggesting that no discernible horizontal gradients were operating along this platform, which could interfere with the interpretation of results.

At each location (disturbed and controls), sampling of mature assemblages was done by means of 10 random quadrats $(25 \times 25 \mathrm{~cm})$ located at least $1 \mathrm{~m}$ apart at the lower algal dominated shore ( $\sim 0.6 \mathrm{~m}$ above Chart Datum) and upper animal dominated shore $(\sim 1.8 \mathrm{~m}$ above $\mathrm{CD})$. Sampling was done at four different times of the year (July 2006, October 2006, January 2007, March 2007) to provide an estimate of temporal variability in the abundance of organisms. Quadrats were not permanent and were randomly selected on each sampling occasion so as to guarantee independence of data. The percentage cover of algal species was estimated from 36 uniformly distributed points and expressed as percentage cover. An arbitrary value of $0.5 \%$ cover was given to species whose position did not match any of the intersections. Barnacle cover was estimated by giving a score from 0 (absent) to $4(100 \%$ cover) in each of the 25 sub-quadrats (Dethier et al., 1993), while mobile animals (limpets and littorinids) were counted and expressed as density per quadrat. Other animals present (e.g. chitons, whelks) were rare in the sampled areas and, although their presence was recorded, they were not further analysed. Sampling of algae was estimated at the highest taxonomic resolution achievable in the field. This included the identification of several organisms to species level, although others were identified to genera. Algae were later grouped into distinct morphological/functional groups which included: leathery and corticated erect algae (e.g. Fucoids, Stypocaulon scoparium; hereafter referred to as frondose algae), coarsely branched algae (e.g. Osmundea spp., articulated coralline algae; hereafter referred to as turf-forming algae), filamentous algae (e.g. Ceramium spp.), ephemeral algae (e.g. Enteromorpha (Ulva) spp., Rivularia sp.) and crustose algae (e.g. Nemoderma sp., encrusting coralline algae).

The influence of the breakwater on organism recruitment was examined by means of $10 \times 10 \mathrm{~cm}$ recruitment plates $(n=5$ per combination of location and tidal height). The selected locations and shore height were as described above. Plates were preferred over experimental clearings since these constitute suitable colonisation substrates for a variety of organisms (at least in the shortterm) and eliminate the influence of non-evident processes that could affect the interpretation of results between the impacted and control locations (Chapman and Underwood, 2008). Hence, if recruitment in the impacted location differs from that of control locations, this is most likely due to the presence of the breakwater and consequent changes in the local physical environment (e.g. water circulation). The plates were made of basaltic rock, the natural substratum in the area, perforated in the centre and screwed to the shore with stainless steel screws at least $1 \mathrm{~m}$ apart. In order to provide temporal replication, after first deployment in July 2007 , plates were retrieved and replaced every three months. A total of three sets of plates were thus available for analysis corresponding to the periods of colonisation of July 2006-October 2006, October 2006-January 2007 and January 2007-April 2007. The percentage cover of algae on recruitment plates was estimated under a dis- secting microscope by overlaying a translucent sheet with 50 uniformly-spaced points and recording the species underneath. A space of $1 \mathrm{~cm}$ was left between the edges of the plate and the beginning of the quantification points as well as to the central hole (used to attach the plate to the shore) to reduce edge effects. Barnacles were counted and expressed as density per $100 \mathrm{~cm}^{2}$. Four sub-samples of $1 \mathrm{~cm}^{2}$ were used where these were too abundant to be counted and the mean of the four sub-samples standardized to $100 \mathrm{~cm}^{2}$. Other animals present were either too rare to be analysed (e.g. bryozoans) or were mobile (limpets and littorinids) and thus it was not possible to be sure in ascribing their presence on plates to recruitment.

Plaster discs were used to examine the effect of the breakwater on the hydrodynamics of the adjacent reef. This was done by screwing three replicate plaster discs ( $\sim 5 \mathrm{~m}$ apart) of known weight per site to mid-shore tidal heights. The loss of mass (dry weight) after one high tide was used as a surrogate for water-motion or wave action (e.g. Lindegarth and Gamfeldt, 2005). Wave action was estimated three times during the study - in July 2006, October 2006 and April 2007. Although the typical large smallscale variation in water-motion suggests that the number of plaster discs used is small, the small size of error bars (see Fig. 6) indicates replication was enough to provide a precise estimate of this variable. We also aimed at quantifying the level of sedimentation by deploying sediment traps in July 2007 (Airoldi, 2003) but this methodology proved rather unfruitful in the intertidal since the majority of the sediment traps were lost after 5 days, probably due to the high resistance of the containers to wave action. As an alternative, the abundance of sediment was estimated as percentage cover while sampling for mature assemblages in subsequent sampling events.

\subsection{Data analysis}

To test for differences in the abundance of the different taxa between the disturbed and control locations, data were analysed using 2-way asymmetrical ANOVAs with time and location as random factors and orthogonal to each other. A general model of the analysis as well as the calculation of the expected mean squares and the consequent determination of denominators for each test

\section{Table 1}

Asymmetrical analysis of variance comparing the disturbed $(I)$ and control (Cs) locations, where: $a=$ times of sampling, $b=$ all locations (the disturbed and 3 controls), $n=$ number of replicates. Both time and location are random and orthogonal with each other.

\begin{tabular}{lll}
\hline Source of variation & $d f$ & Expected mean square \\
\hline Time $=T$ & $a-1$ & $\sigma_{\mathrm{e}}^{2}+n \sigma_{T \times L}^{2}+b n \sigma_{T}^{2}$ \\
Location $=L$ & $b-1$ & $\sigma_{\mathrm{e}}^{2}+n \sigma_{T \times L}^{2}+a n \sigma_{L}^{2}$ \\
${ }^{\mathrm{e} I} v s . C^{\prime} s$ & 1 & $\sigma_{\mathrm{e}-I}^{2}+n \sigma_{T \times I v s . C^{\prime} s}^{2}+a n \sigma_{L}^{2}+a n \beta_{I v s . C^{\prime} s}^{2}$ \\
${ }^{\mathrm{d} C} C^{\prime} s$ & $b-2$ & $\sigma_{\mathrm{e}-C^{\prime} s}^{2}+n \sigma_{T \times C^{\prime} s}^{2}+a n \sigma_{C^{\prime} s}^{2}$ \\
${ }^{\mathrm{c}} T \times L$ & $(a-1)(b-1)$ & $\sigma_{\mathrm{e}}^{2}+n \sigma_{T \times L}^{2}$ \\
${ }^{\mathrm{b}} T \times I$ vs. C's & $(a-1)$ & $\sigma_{\mathrm{e}-I}^{2}+n \sigma_{T \times L}^{2}+n \sigma_{T \times I v s . C^{\prime} s}^{2}$ \\
${ }^{\mathrm{a}} T \times C$ $s$ & $(a-1)(b-2)$ & $\sigma_{\mathrm{e}-C^{\prime} s}^{2}+n \sigma_{T \times C^{\prime} s}^{2}$ \\
Residual & $a b(n-1)$ & $\sigma_{\mathrm{e}}^{2}$ \\
Res $I$ & $a(n-1)$ & $\sigma_{\mathrm{e}-I}^{2}$ \\
Res C's & $a(b-1)(n-1)$ & $\sigma_{\mathrm{e}-C^{\prime} s}^{2}$ \\
\hline
\end{tabular}

Adapted from Terlizzi et al. (2005).

a Tested over Res C's.

b Tested over the residual if $T \times C$ 's can be eliminated from the model (not significant at $\alpha=0.25$, Underwood, 1997); tested over $T \times C$ 's otherwise. These tests assume equivalence among $\sigma_{T \times L}^{2}$ and $\sigma_{T \times C^{\prime} s}^{2}$ (see Glasby, 1997).

c Tested over the residual.

d Tested over $T \times C$ 's.

e Tested over the residual if $T \times L$ and $C$ 's can be eliminated from the model; tested over $T \times L$ if $C$ s can be eliminated but not $T \times L$; tested over C's if this term cannot be eliminated from the model. These tests assume equivalence among $\sigma_{T \times I v s . C^{\prime} s}^{2}, \sigma_{T \times C^{\prime} s}^{2}$ and $\sigma_{T \times L}^{2}$, and among $\sigma_{L}^{2}$ and $\sigma_{C^{\prime} s^{\prime}}^{2}$. 

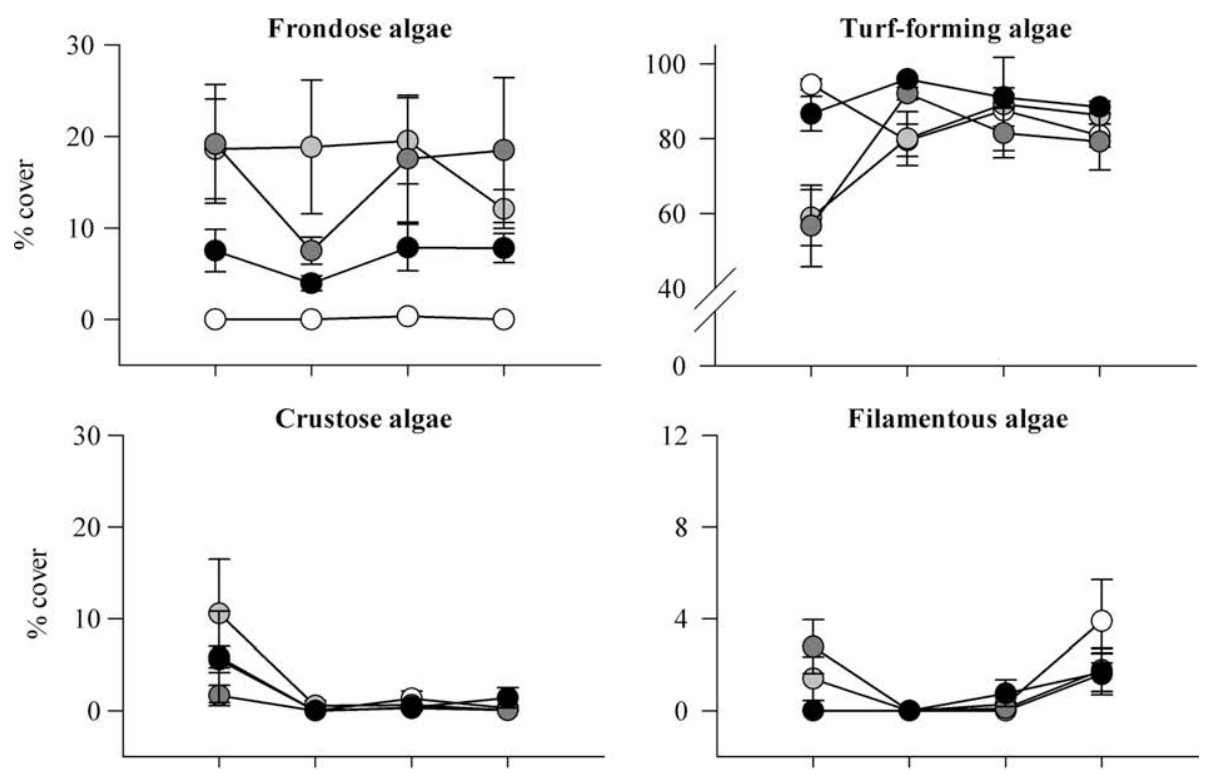

Jul '06 Oct '06 Jan '07 Apr '07

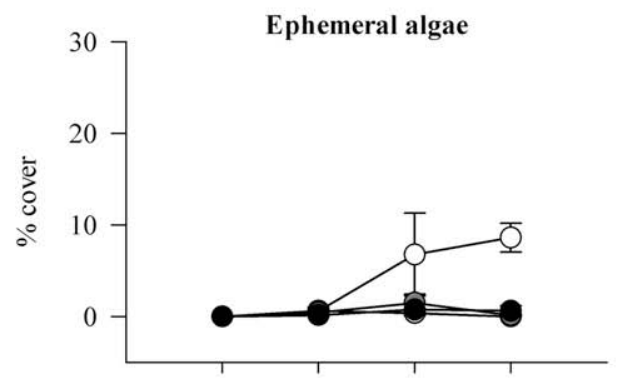

Jul '06 Oct '06 Jan '07 Apr'07

Fig. 2. Mean (+SE)\% cover of lower shore conspicuous taxa in the impacted and control locations.

Table 2

Asymmetrical analysis of variance comparing the abundance of conspicuous lower shore taxa in the disturbed $(I)$ and control (Cs) locations.

\begin{tabular}{|c|c|c|c|c|c|c|c|c|c|c|c|}
\hline \multirow[t]{2}{*}{ Source } & \multirow[t]{2}{*}{$d f$} & \multicolumn{2}{|c|}{ Frondose algae } & \multicolumn{2}{|c|}{ Turf-forming algae } & \multicolumn{2}{|c|}{ Crustose algae } & \multicolumn{2}{|c|}{ Filamentous algae } & \multicolumn{2}{|c|}{ Ephemeral algae } \\
\hline & & MS & $F$ & MS & $F$ & MS & $F$ & MS & $F$ & MS & $F$ \\
\hline$T$ & 3 & 0.17 & & $1.49 E^{3}$ & & 1.72 & & 2.00 & & 2.13 & \\
\hline$L$ & 3 & 45.97 & & $153 E^{3}$ & & 0.66 & & 0.12 & & 2.49 & \\
\hline I vs. C's & 1 & 126.77 & $22.76^{*}$ & $3.55 E^{2}$ & 0.17 & 1.64 & & 0.11 & 0.43 & 7.16 & \\
\hline C's & 2 & 5.57 & $9.24^{*}$ & $2.11 E^{3}$ & 3.41 & 0.17 & 1.76 & 0.13 & 0.46 & 0.15 & 2.13 \\
\hline$T \times L$ & 9 & 0.44 & 0.45 & $1.07 E^{3}$ & $3.01^{* * *}$ & 0.32 & 1.80 & 0.24 & 1.53 & 0.45 & $2.98^{* *}$ \\
\hline$T \times I$ vs. $C^{\prime} s$ & 3 & 0.12 & 0.13 & $1.98 E^{3}$ & 3.20 & 0.78 & $4.32^{* *}$ & 0.15 & 0.51 & 1.22 & $8.01^{* * *}$ \\
\hline$T \times C^{\prime} s$ & 6 & 0.60 & 0.46 & $6.20 E^{2}$ & 1.42 & 0.10 & 0.52 & 0.29 & 1.68 & 0.07 & 0.44 \\
\hline Residual & 144 & 0.99 & & $3.57 E^{2}$ & & 0.18 & & 0.16 & & 0.15 & \\
\hline Res $I$ & 36 & 0.05 & & $1.19 E^{2}$ & & 0.17 & & 0.12 & & 0.13 & \\
\hline Res C's & 108 & 1.30 & & $4.36 E^{2}$ & & 0.02 & & 0.17 & & 0.16 & \\
\hline Transformation & & $\operatorname{Ln}(x+1)$ & & & & $x^{0.1}$ & & $x^{0.1}$ & & $x^{0.1}$ & \\
\hline Cochran's test & & $C=0.17$ & & $C=0.27^{* *}$ & & $C=0.17$ & & $C=0.15$ & & $C=0.13$ & \\
\hline
\end{tabular}

Significant terms in bold: ${ }^{*} p<0.05,{ }^{* *} p<0.01,{ }^{* * *} p<0.001$.

$E=\times 10$.

was adapted from Terlizzi et al. (2005) and is presented in Table 1. Generally, the factor location was partitioned into two components: one contrasting the impacted and control locations ( $I$ vs. $C$ 's) and the other contrasting control locations among each other $(C ' s)$. This was also true for the time $\times$ location interaction and for the residuals associated with variability among quadrats, respectively within $I$ and C's (see Terlizzi et al., 2005 for a detailed description of these procedures). Prior to analysis, Cochran's test was used to check for problems of heteroscedascity and data were transformed where appropriate (Underwood, 1997). Where heterogeneity of variances persisted, data were analysed untransformed but a more conservative $P$-value was used (Underwood, 1997; Blockley and Chapman, 2006).

\section{Results}

\subsection{Mature assemblages}

Patterns of distribution in the disturbed and control locations were variable among the different taxa examined. As expected, on the lower shore algal dominated assemblage (Fig. 2, Table 2) the cover of frondose algae was lower in the disturbed location 
and this was consistent in time despite variability among control locations. Crustose algae also occurred at lower abundances in the disturbed location although this was temporally variable. The space released by the reduction in cover of frondose and crustose algae in the disturbed location was occupied by ephemeral algae, which increased in cover although its cover varied with time. Turf-forming and filamentous algae showed no clear variation being similarly distributed across the rocky platform.

On the upper animal dominated shore (Fig. 3, Table 3), both the cover of barnacles and the number of limpets were consistently lower in the disturbed location. Again, ephemerals seemed to take advantage from the release in competition and were consistently more abundant in the upper shore of the disturbed location. Although the abundance of littorinids in the disturbed locations tended to be lower than the mean abundance among control locations, this was not statistically significant.

\subsection{Early successional assemblages}

Recruitment of organisms to lower shore settlement plates was also variable and depended on taxa (Fig. 4, Table 4). Recruitment to panels was dominated by ephemeral species and this was similar in the disturbed and control locations. The colonisation of turfforming algae was temporally variable among control locations although no clear difference was detected between the disturbed and its overall mean abundance in control locations. In contrast, the abundance of filamentous algae was consistently lower in the disturbed location. The abundance of crustose algae also differed between the disturbed and control locations, but this was variable in time. The barnacle $C$. stellatus also recruited to lower shore plates, albeit at lower abundances compared to that recorded on upper shore plates. However, although recruitment tended to be lower in the disturbed location, this was not statistically significant.

On the upper shore recruitment plates (Fig. 5, Table 5), the only discernible algal recruitment was that of ephemeral species, which were present at larger abundances in the disturbed location during most of the study period. Filamentous and crustose algae were sporadically recorded but were too rare to be analysed. In contrast, barnacle recruitment was virtually null in the disturbed location, whilst reaching a mean number of $146 \pm 33$ (mean $\pm 1 \mathrm{SE}$ ) recruits per plate among control locations during the peak of recruitment.
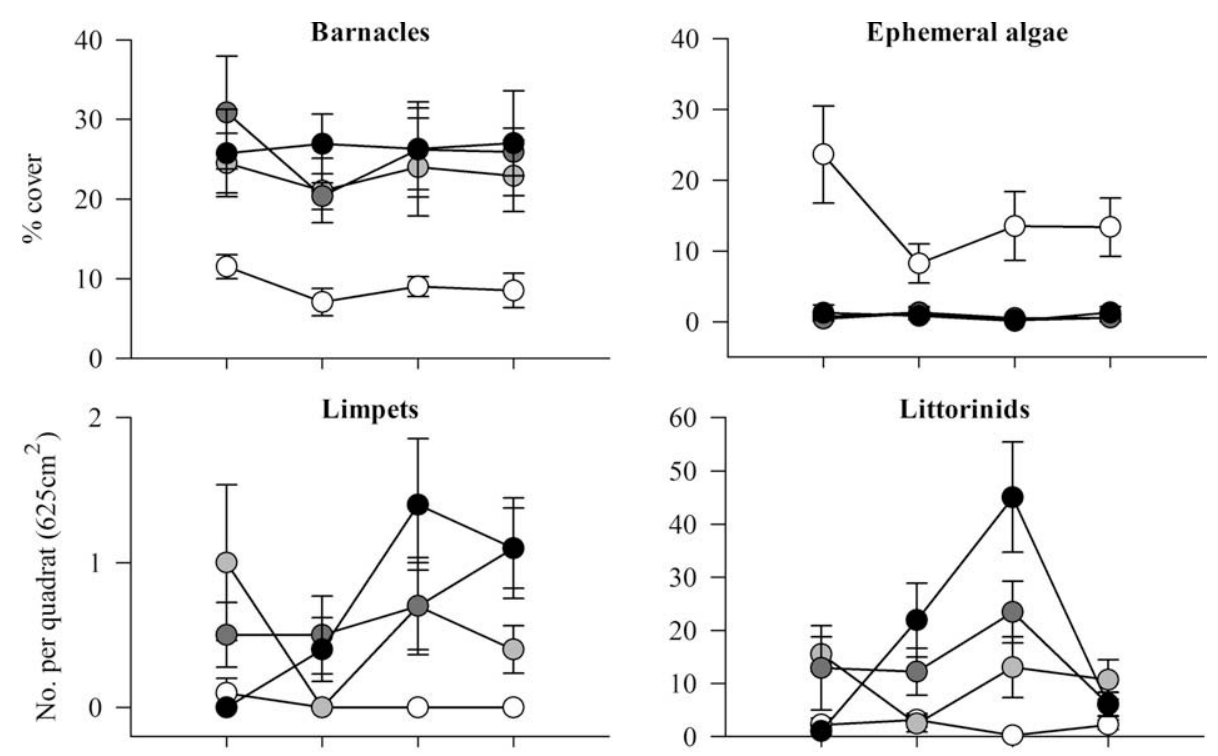

Jul '06 Oct '06 Jan '07 Apr '07

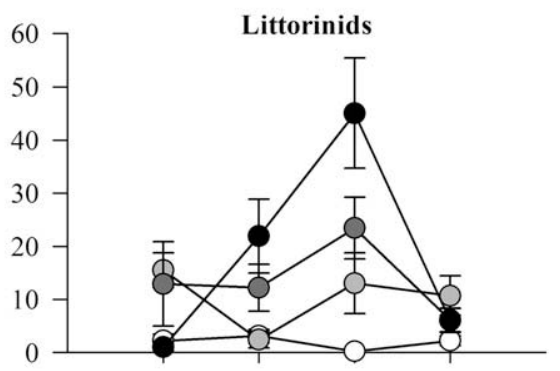

Jul '06 Oct '06 Jan '07 Apr'07

$$
-\mathrm{O}-\mathrm{I}-\mathrm{O}-\mathrm{C} 1-\mathrm{C} 2 \longrightarrow \mathrm{C} 3
$$

Fig. 3. Mean (+SE)\% cover of upper shore conspicuous taxa or number of limpets and littorinids per quadrat $\left(625 \mathrm{~cm}^{2}\right)$ in the impacted and control locations.

Table 3

Asymmetrical analysis of variance comparing the abundance of conspicuous upper shore taxa in the disturbed $(I)$ and control (C's) locations.

\begin{tabular}{|c|c|c|c|c|c|c|c|c|c|}
\hline \multirow[t]{2}{*}{ Source } & \multirow[t]{2}{*}{$d f$} & \multicolumn{2}{|c|}{ Barnacles } & \multicolumn{2}{|l|}{ Limpets } & \multicolumn{2}{|c|}{ Littorinids } & \multicolumn{2}{|c|}{ Ephemeral algae } \\
\hline & & MS & $F$ & MS & $F$ & MS & $F$ & MS & $F$ \\
\hline$T$ & 3 & $1.25 E^{2}$ & & 0.60 & & 16.99 & & 0.14 & \\
\hline$L$ & 3 & $2.69 E^{3}$ & & 1.30 & & 31.93 & & 6.78 & \\
\hline I vs. C's & 1 & $7.80 E^{3}$ & $61.01^{*}$ & 3.54 & $9.27^{*}$ & 87.94 & 4.58 & 19.97 & $68.73^{* *-}$ \\
\hline C's & 2 & $1.28 E^{2}$ & 2.17 & 0.18 & 0.40 & 3.93 & & 0.18 & 0.67 \\
\hline$T \times L$ & 9 & $4.01 E^{1}$ & 0.21 & 0.38 & $2.24^{*}$ & 19.21 & $7.58^{* * *}$ & 0.29 & 1.41 \\
\hline$T \times I$ vs. $C^{\prime} S$ & 3 & $2.67 E^{0}$ & 0.01 & 0.25 & 0.57 & 18.58 & 0.95 & 0.31 & 1.53 \\
\hline$T \times C^{\prime} s$ & 6 & $5.88 E^{1}$ & 0.24 & 0.45 & 1.99 & 19.52 & $6.10^{* * *}$ & 0.28 & 1.15 \\
\hline Residual & 144 & $1.94 E^{2}$ & & 0.17 & & 2.53 & & 0.21 & \\
\hline Res I & 36 & $2.83 E^{1}$ & & 0.01 & & 0.54 & & 0.10 & \\
\hline $\operatorname{Res} C$ 's & 108 & $2.50 E^{2}$ & & 0.22 & & 3.20 & & 0.24 & \\
\hline Transformation & & & & $\operatorname{Ln}(x+1)$ & & Sq-rt & & $x^{0.1}$ & \\
\hline Cochran's & & $C=0.16$ & & $C=0.16$ & & $C=0.15$ & & $C=0.09$ & \\
\hline
\end{tabular}

Significant terms in bold: $p$-values as in Table 2. 


\subsection{Physical environment}

As expected, plaster dissolution was twofold greater in control sites than in the area sheltered by the breakwater (Fig. 6, Table 6) and this was consistent in time revealing that the breakwater exerts a putative impact on this part of the rocky platform. Accumulation of sediment occurred lower on the shore in the impacted location trapped inside mats of turf-forming algae although this was temporally variable. A peak of sediment accumulation was recorded in October 2006 with a mean percentage cover of $19.7 \pm 4.4$ (mean $\pm \mathrm{SE}$ ), whilst lower abundances were recorded in January 2007 (3.9\% \pm 1.6$)$ and April 2007 (6.7\% \pm 3.7$)$. No sedimentation was recorded on the lower shore of control sites, or on the upper shores of either the disturbed or control locations.

\section{Discussion}

Generally, the area sheltered by the breakwater supported a structurally and functionally different assemblage than that recorded in control locations and this was especially evident in the
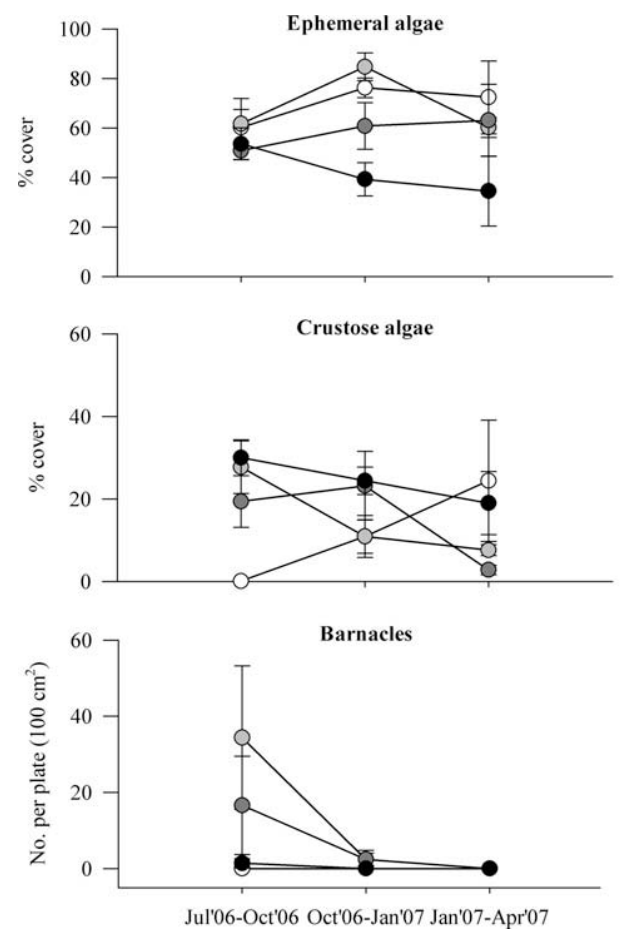

Fig. 4. Mean (+SE)\% cover of lower shore conspicuous taxa on recruitment plates in the impacted and control locations.

Table 4

Asymmetrical analysis of variance comparing the abundance of conspicuous lower shore taxa on recruitment plates in the disturbed $(I)$ and control $(C ' s)$ locations.

\begin{tabular}{|c|c|c|c|c|c|c|c|c|c|c|c|}
\hline \multirow[t]{2}{*}{ Source } & \multirow[t]{2}{*}{$d f$} & \multicolumn{2}{|c|}{ Ephemeral algae } & \multicolumn{2}{|c|}{ Filamentous algae } & \multicolumn{2}{|c|}{ Crustose algae } & \multicolumn{2}{|c|}{ Turf-forming algae } & \multicolumn{2}{|l|}{ Barnacles } \\
\hline & & MS & $F$ & MS & $F$ & MS & $F$ & MS & $F$ & MS & $F$ \\
\hline$T$ & 2 & $4.50 E^{2}$ & & 8.44 & & $1.77 E^{2}$ & & 2.10 & & $1.05 E^{3}$ & \\
\hline$L$ & 3 & $2.41 E^{3}$ & & 2.69 & & $4.42 E^{2}$ & & 5.40 & & $5.00 E^{2}$ & \\
\hline I vs. C's & 1 & $1.92 E^{3}$ & 0.73 & 5.83 & $6.09^{*}$ & $4.80 E^{2}$ & & 4.49 & 0.74 & $4.54 E^{2}$ & 1.13 \\
\hline C's & 2 & $2.65 E^{3}$ & 3.99 & 1.13 & 0.62 & $4.23 E^{2}$ & 2.37 & 5.86 & 0.75 & $5.22 E^{2}$ & 1.22 \\
\hline$T \times L$ & 6 & $5.15 E^{2}$ & 1.19 & 1.23 & 1.28 & $6.28 E^{2}$ & $3.02^{*}$ & 6.07 & $14.08^{* * *}$ & $4.00 E^{2}$ & 1.81 \\
\hline$T \times I$ vs. C's & 2 & $2.18 E^{2}$ & 0.33 & 0.06 & 0.03 & $1.53 E^{3}$ & $7.34^{* *}$ & 2.67 & 0.34 & $3.50 E^{2}$ & 0.82 \\
\hline$T \times C^{\prime} S$ & 4 & $6.64 E^{2}$ & 1.59 & 1.81 & 1.73 & $1.79 E^{2}$ & 1.21 & 7.76 & $16.04^{* * *}$ & $4.26 E^{2}$ & 1.44 \\
\hline Residual & 48 & $4.31 E^{2}$ & & 0.96 & & $2.08 E^{2}$ & & 0.43 & & $2.21 E^{2}$ & \\
\hline Res I's & 12 & $4.74 E^{2}$ & & 0.69 & & $3.88 E^{2}$ & & 0.27 & & 0 & \\
\hline Res C's & 36 & $4.17 E^{2}$ & & 1.05 & & $1.48 E^{2}$ & & 0.48 & & $2.95 E^{2}$ & \\
\hline Transformation & & & & $\operatorname{Ln}(x+1)$ & & & & $\operatorname{Ln}(x+1)$ & & & \\
\hline Cochran's & & $C=0.21$ & & $C=0.23$ & & $C=0.43^{* *}$ & & $C=0.25$ & & $C=0.67^{* *}$ & \\
\hline
\end{tabular}

Significant terms in bold: $p$-values as in Table 2. upper eulittoral. At this tidal height, ephemeral algae replaced the dominant space occupier, the barnacle C. stellatus, in the disturbed area and persisted throughout the year. The shift between animal dominated and algal dominated assemblages along a decreasing gradient of wave action is common to temperate regions worldwide even though the processes that structure these communities can differ among locations (see Jenkins et al., 2008 and references therein). In European coasts, much experimental work has convincingly shown that grazing by patellid limpets limits the growth of macroalgae in wave-beaten shores and that their removal leads to a change in dominance between barnacles and mussels, and macroalgae (e.g. Hawkins, 1981; Jenkins et al., 2005; Arrontes et al., 2004; Coleman et al., 2006). Similarly, the reduced abundance of patellid limpet in the sheltered area probably led to the divergence in structure of assemblages found between the disturbed and control locations. Such shift in dominance at the upper eulittoral zone has important ecological and energetic consequences by altering a net consumer ecosystem into one dominated by producers.

At the lower algal dominated shore, important differences in the assemblage structure were also clear with ephemeral algae
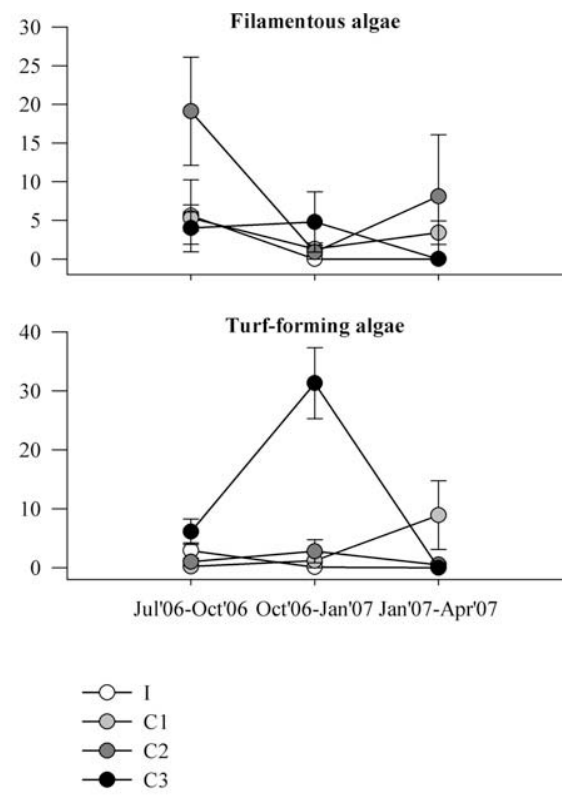

Significant terms in bold: p-values as in Table 2. 

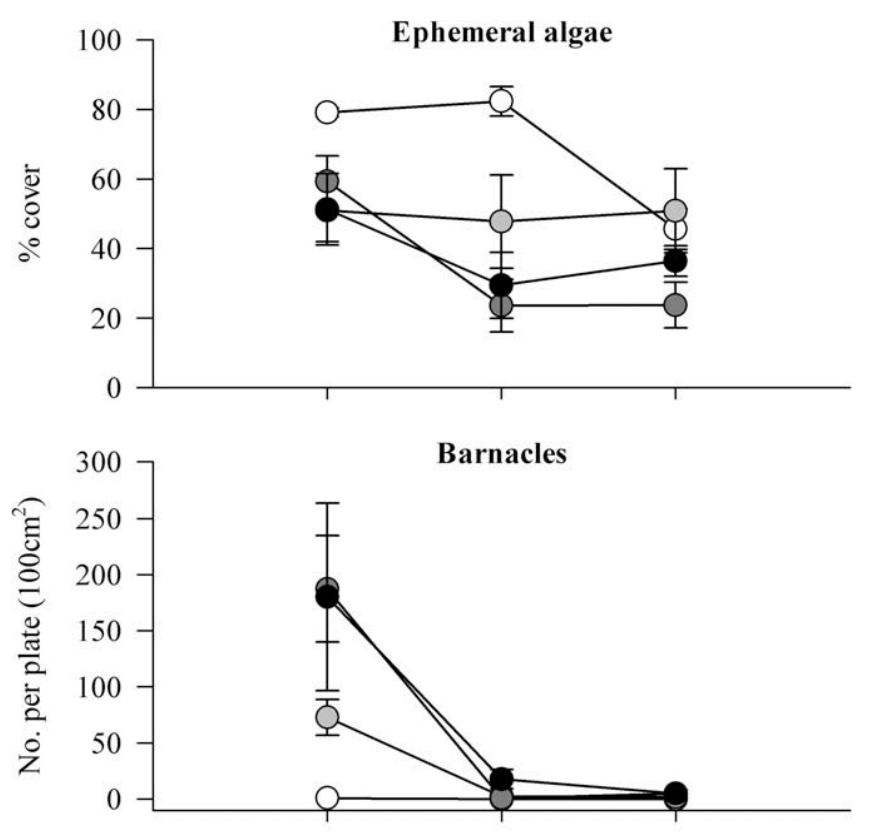

Jul'06-Oct'06 Oct'06-Jan'07 Jan'07-Apr'07

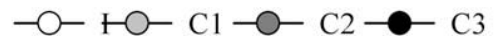

Fig. 5. Mean $(+\mathrm{SE}) \%$ cover of upper shore conspicuous taxa on recruitment plates in the impacted and control locations.

Table 5

Asymmetrical analysis of variance comparing the abundance of conspicuous upper shore taxa on recruitment plates in the disturbed $(I)$ and control $(C s)$ locations.

\begin{tabular}{|c|c|c|c|c|c|}
\hline \multirow[t]{2}{*}{ Source } & \multirow[t]{2}{*}{$d f$} & \multicolumn{2}{|c|}{ Ephemeral algae } & \multicolumn{2}{|l|}{ Barnacles } \\
\hline & & MS & $F$ & MS & $F$ \\
\hline$T$ & 2 & $2.31 E^{3}$ & & 52.13 & \\
\hline$L$ & 3 & $3.40 E^{3}$ & & 20.24 & \\
\hline I vs. C's & 1 & $8.54 E^{3}$ & & 55.14 & \\
\hline C's & 2 & $8.30 E^{2}$ & 1.67 & 2.80 & 1.48 \\
\hline$T \times L$ & 6 & $8.38 E^{2}$ & $2.43^{*}$ & 5.80 & $7.81^{* * *+}$ \\
\hline$T \times I$ vs. C's & 2 & $1.52 E^{3}$ & $4.41^{*}$ & 13.61 & $7.17^{*}$ \\
\hline$T \times C ' s$ & 4 & $4.97 E^{2}$ & 1.15 & 1.90 & 2.03 \\
\hline Residual & 48 & $3.45 E^{2}$ & & 0.74 & \\
\hline Res I & 12 & $9.04 E^{1}$ & & 0.17 & \\
\hline $\operatorname{Res} C^{\prime} S$ & 36 & $4.30 E^{2}$ & & 0.93 & \\
\hline Transformation & & & & $\operatorname{Ln}(x+1)$ & \\
\hline Cochran's & & $C=0.22$ & & $C=0.26$ & \\
\hline
\end{tabular}

Significant terms in bold: $p$-values as in Table 2.

Table 6

Asymmetrical analysis of variance comparing plaster dissolution ( $\mathrm{g}$ of dry weight) in the disturbed $(I)$ and control $(C$ 's) locations.

\begin{tabular}{llll}
\hline Source & $d f$ & MS & $F$ \\
\hline$T$ & 2 & 0.30 & \\
$L$ & 3 & 76.89 & $\mathbf{6 1 . 1 7}^{* * *}$ \\
$I$ vs. C's & 1 & 222.17 & 1.26 \\
''s & 2 & 4.26 & 0.63 \\
$T \times L$ & 6 & 2.28 & 0.02 \\
$T \times I$ vs. C's & 2 & 0.09 & 0.54 \\
$T \times C$ 's & 4 & 3.38 & \\
Residual & 24 & 3.63 & \\
Res $I$ & 6 & 1.92 & \\
Res C's & 12 & 6.31 & \\
Transformation & & $C=0.36$ & \\
Cochran's & & & \\
\hline
\end{tabular}

Significant terms in bold: $p$-values as in Table 2.

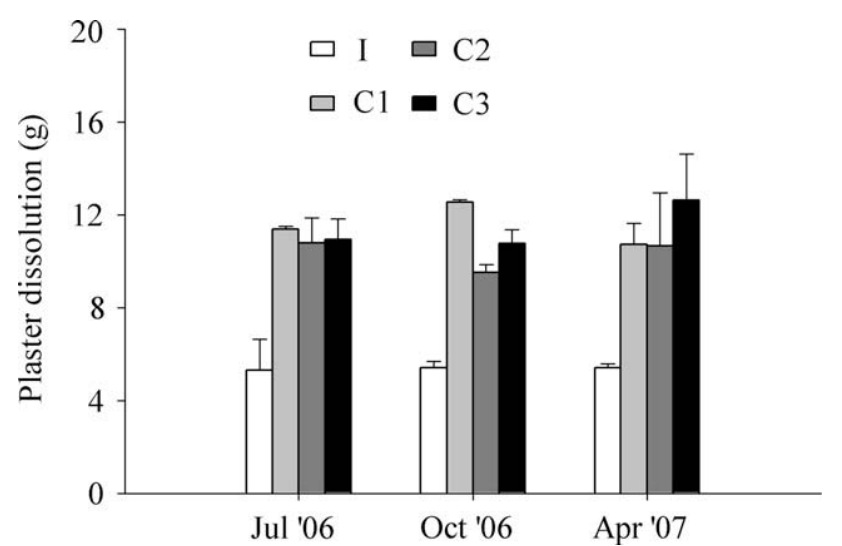

Fig. 6. Mean ( $+\mathrm{SE}$ ) plaster dissolution in $\mathrm{g}$ (dry weight) in the impacted and control locations.

similarly replacing frondose algae in the disturbed location. The hydrodynamic forces generated by the breaking of waves in the intertidal are known to limit the size and survival of larger plants so that these generally become restricted to more sheltered conditions (Blanchette, 1997). However, this was not the case. While our attempts to estimate the intensity of sedimentation were not particularly successful, they do suggest that sediment tended to accumulate in the disturbed area and this is known to negatively affect the colonisation of space by erect algae, while having no discernible effect on the spatial dominance of algal turfs (Airoldi, 1998).

Significant differences between the disturbed and control locations were also evident during the early successional stages of assemblage development. During the peak of barnacle settlement, these recruited in abundance on upper shore plates in the control locations but not in the sheltered area, where ephemeral algae composed the bulk of the early successional assemblage. In the lower shore, recruitment of filamentous algae was also lower in the disturbed location than on the adjacent exposed controls. As for adult populations, exposure to wave action is known to influence the recruitment and survival of a number of intertidal animals and plants. For instance, low energy waves were shown to remove up to $99 \%$ of recently settled zygotes of Ascophyllum nodosum, and thus explaining its inability to colonise exposed locations (Vadas et al., 1990). Although populations of the barnacle C. stellatus predominate on wave-exposed shores (e.g. Jenkins, 2005), their ability to colonise sheltered shores does not seem limited by the abundance of larvae, which actually tend to concentrate on sheltered bays (Jenkins and Hawkins, 2003), but by post-settlement processes that limit the ability of barnacles to settle (Jenkins and Hawkins, 2003) or cause the mortality of recently settled animals (e.g. the sweeping of frondose algae, Jenkins et al., 1999). In the present study, barnacle settlement on plates in the sheltered location was probably limited by competition for space with ephemeral algae. Alternatively, both the recruitment of barnacles and filamentous algae in the sheltered areas may have been driven by the breakwater-induced variations in water-motion, which likely influence the dispersion of propagules and nutrients (Mullineaux and Butman, 1991; Abelson and Denny, 1997).

Although the non-interspersion of controls and the disturbed location is a potential confounding factor (Underwood, 1994), the range of responses of individual taxa, or the assemblage as a whole, to the sheltering by the breakwater could easily be interpreted in light of the vast literature examining the influence of wave action as a structuring process. In addition, the lack of spatial correlation in the abundance of the various taxa among control locations, indicating that no major gradients are affecting the horizontal distribu- 
tion of organisms on this rocky platform, suggests that results have not been affected by the segregation of controls in relation to the impacted location.

Anecdotal evidence suggests the assemblage that developed as a consequence of the artificial sheltering is similar to that of sheltered shores in warmer-temperate regions (Airoldi, 2001; Boaventura et al., 2002). However, caution is needed as there is evidence that the impacts of natural and artificial rocky reefs on the structure of marine assemblages can differ, while being similar in the way they may affect the environment (e.g. wave exposure) (Barros et al., 2001; Knott et al., 2004; Vaselli et al., 2008).

\section{Conclusion}

The present study has shown that the construction of breakwaters can have a strong effect on the structure and functioning of adjacent rocky intertidal communities. The artificial sheltering of naturally exposed shores is itself a strong impact and here resulted in the development of a structurally and functionally divergent assemblage. This study adds to the existing literature by showing that anthropogenic activities such as the construction of artificial structures can have important ecological as well as energetic consequences for the functioning of the local ecosystem.

\section{Acknowledgements}

The present study was supported by Secretaria Regional do Ambiente e do Mar and Universidade dos Açores. The Câmara Municipal das Lajes do Pico and Escola Básica Integrada e Secundária das Lajes do Pico provided logistic support. G.M. Martins and F.M. Wallenstein were supported by PhD Grants from FCT (SFRH/ BD/22009/2005 and SFRH/BD/27466/2006, respectively). A.F. Amaral was supported by Secretaria Regional do Ambiente e do Mar.

\section{References}

Abelson, A., Denny, M., 1997. Settlement of marine organisms in flow. Annual Review of Ecology Systematics 28, 317-339.

Airoldi, L., 1998. Roles of disturbance, sediment stress, and substratum retention on spatial dominance in algal turf. Ecology 79, 2759-2770.

Airoldi, L., 2001. Distribution and morphological variation of low-shore algal turfs. Marine Biology 138, 1233-1239.

Airoldi, L., 2003. The effects of sedimentation on rocky coast assemblages. Oceanography and Marine Biology: An Annual Review 41, 161-236.

Airoldi, L., Beck, M.W., 2007. Loss, status and trends for coastal marine habitats of Europe. Oceanography and Marine Biology: An Annual Review 45, 345-405.

Airoldi, L., Hawkins, S.J., 2007. Negative effects of sediment deposition on grazing activity and survival of the limpet Patella vulgata. Marine Ecology Progress Series 332, 235-240.

Arrontes, J., Arenas, F., Fernandez, C., Rico, J.M., Oliveros, J., Martinez, B., Viejo, R.M., Alvarez, D., 2004. Effect of grazing by limpets on mid-shore species assemblages in northern Spain. Marine Ecology Progress Series 277, 117-133.

Ávila, S.P., Santos, A.C., Penteado, A.M., Rodrigues, A.M., Quintino, I., Machado, M.I., 2005. The molluscs of the intertidal algal turf in the Azores. Iberus 23, 67-76.

Barros, F., Underwood, A.J., Lindegarth, M., 2001. The influence of rocky reefs on structure of benthic macrofauna in nearby soft-sediments. Estuarine, Coastal and Shelf Science 52, 191-199.

Benedetti-Cecchi, L., Pannacciulli, F., Bulleri, F., Moschella, P.S., Airoldi, L., Relini, G., Cinelli, F., 2001. Predicting the consequences of anthropogenic disturbance: large-scale effects of loss of canopy algae on rocky shores. Marine Ecology Progress Series 137, 137-150.

Bertasi, F., Colangelo, M.A., Abbiati, M., Ceccherelli, V.U., 2007. Effects of an artificial protection structure on the sandy shore macrofaunal community: the special case of Lido di Dante (Northern Adriatic Sea). Hydrobiologia 586, 277-290.

Blanchette, C.A., 1997. Size and survival of intertidal plants in response to wave action: a case study with Fucus gardneri. Ecology 78, 1563-1578.

Blockley, D.J., Chapman, M.G., 2006. Recruitment determines differences between assemblages on shaded or unshaded seawalls. Marine Ecology Progress Series $327,27-36$.

Boaventura, D., Ré, P., Fonseca, L.C., Hawkins, S.J., 2002. Intertidal rocky shores communities of the continental Portuguese coast: analysis of distribution patterns. Marine Ecology 23, 69-90.

Bulleri, F., 2005. Role of recruitment in causing differences between intertidal assemblages on seawalls and rocky shores. Marine Ecology Progress Series 287, 53-65.
Bulleri, F., Airoldi, L., 2005. Artificial marine structures facilitate the spread of a nonindigenous green alga, Codium fragile ssp tomentosoides, in the north Adriatic Sea. Journal of Applied Ecology 42, 1063-1072.

Bulleri, F., Chapman, M.G., 2004. Intertidal assemblages on artificial and natura habitats in marinas on the north-west coast of Italy. Marine Biology 145, 381 391.

Bulleri, F., Chapman, M.G., Underwood, A.J., 2004. Patterns of movement of the limpet Cellana tramoserica on rocky shores and retaining seawalls. Marine Ecology Progress Series 281, 121-129.

Chapman, M.G., 2003. Paucity of mobile species on constructed seawalls: effects o urbanization on biodiversity. Marine Ecology Progress Series 264, 21-29.

Chapman, M.G., Bulleri, F., 2003. Intertidal seawalls - new features of landscape in intertidal environments. Landscape and Urban Planning 62, 159-172.

Chapman, M.G., Underwood, A.J., 2008. Scales of variation of gastropod densities over multiple spatial scales: comparison of common and rare species. Marine Ecology Progress Series 354, 147-160.

Chapman, M.G., Underwood, A.J., Skilleter, G.A., 1995. Variability at different spatial scales between a subtidal assemblage exposed to the discharge of sewage and two control assemblages. Journal of the Experimental Marine Biology and Ecology 189, 103-122.

Clynick, B.G., Chapman, M.G., Underwood, A.J., 2008. Fish assemblages associated with urban structures and natural reefs in Sydney, Australia. Austral Ecology 33, 140-150.

Coleman, R.A., Underwood, A.J., Benedetti-Cecchi, L., Aberg, P., Arenas, F., Arrontes, J., Castro, J., Hartnoll, R.G., Jenkins, S.R., Paula, J., Della Santina, P., Hawkins, S.J. 2006. A continental scale evaluation of the role of limpet grazing on rocky shores. Oecologia 147, 556-564.

Cuadrado, D.G., Gómez, E.A., Ginsberg, S.S., 2005. Tidal and longshore sediment transport associated to a coastal structure. Estuarine, Coastal and Shelf Science 62, 291-300.

Dethier, M.N., Graham, E.S., Cohen, S., Tear, L.M., 1993. Visual versus random-point percent cover estimations: "objective" is not always better. Marine Ecology Progress Series 96, 93-100.

Glasby, T.M., 1997. Analysing data from post-impact studies using asymmetrical analysis of variance: a case study of epibiota on marinas. Australian Journal of Ecology 22, 448-459.

Glasby, T.M., Connell, S.D., Holloway, M.G., Hewitt, C.L., 2007. Nonindigenous biota on artifical structures: could habitat creation facilitate biological invasions? Marine Biology 151, 887-895.

Goodsell, P.J., Chapman, M.G., Underwood, A.J., 2007. Differences between biota in anthropogenically fragmented habitats and in naturally patchy habitats. Marine Ecology Progress Series 351, 15-23.

Hawkins, S.J., 1981. The influence of Patella grazing on the fucoid-barnacle mosaic on moderately exposed rocky shores. Kieler Meeresforsch, 537-543.

Jenkins, S.R., 2005. Larval habitat selection, not larval supply, determines settlement patterns and adult distribution in two chthamalid barnacles. Journal of Animal Ecology 74, 893-904.

Jenkins, S.R., Coleman, R.A., Della Santina, P., Hawkins, S.J., Burrows, M.T., Hartnoll, R.G., 2005. Regional scale differences in the determinism of grazing effects in the rocky intertidal. Marine Ecology Progress Series 287, 77-86.

Jenkins, S.R., Hawkins, S.J., 2003. Barnacle larval supply to sheltered rocky shores: a limiting factor? Hydrobiologia 503, 143-151.

Jenkins, S.R., Moore, P., Burrows, M.T., Garbary, D.J., Hawkins, S.J., Ingólfsson, A., Sebens, K.P., Snelgrove, P.V.R, Wethey, D.S, Woodin, S.A, 2008, Comparative ecology of North Atlantic shores: do differences in players matter? Ecology 89, s3-s23.

Jenkins, S.R., Norton, T.A., Hawkins, S.J., 1999. Settlement and post-settlement interactions between Semibalanus balanoides (L) (Crustacea: Cirripedia) and three species of fucoid canopy algae. Journal of the Experimental Marine Biology and Ecology 236, 49-67.

Jonsson, P.R., Granhag, L., Moschella, P.S., Åberg, P., Hawkins, S.J., 2006. Interactions between wave action and grazing control the distribution of intertidal macroalgae. Ecology 87, 1169-1178.

Kelaher, B.P., Chapman, M.G., Underwood, A.J., 1998. Changes in benthic assemblages near boardwalks in temperate urban mangrove forests. Journal of Experimental Marine Biology and Ecology 228, 291-307.

Knott, N.A., Underwood, A.J., Chapman, M.G., Glasby, T.M., 2004. Epibiota on vertical and on horizontal surfaces on natural reefs and on artificial structures. Journal of the Marine Biological Association of the United Kingdom 84, 1117-1130.

Lindegarth, M., Gamfeldt, L., 2005. Comparing categorical and continuous ecological analyses: effects of "wave exposure" on rocky shores. Ecology 86, 1346-1357.

Mangialajo, L., Chiantore, M., Cattaneo-Vietti, R., 2008. Loss of fucoid algae along gradient of urbanisation, and structure of benthic assemblages. Marine Ecology Progress Series 358, 63-74.

Martins, G.M., Thompson, R.C., Hawkins, S.J., Neto, A.I., Jenkins, S.R., 2008. Rocky intertidal community structure in oceanic islands: scales of spatial variability. Marine Ecology Progress Series 356, 15-24.

McQuaid, C.D., Lindsay, T.L., 2000. Effect of wave exposure on growth and mortality rates of the mussel Perna perna: bottom-up regulation of intertidal populations. Marine Ecology Progress Series 206, 147-154.

Morton, B., Britton, J.C., Martins, A.M.F., 1998. Coastal ecology of the Azores. Sociedade Afonso Chaves, Ponta Delgada.

Mullineaux, L.S., Butman, C.A., 1991. Initial contact, exploration and attachment of barnacle (Balanus amphitrite) cyprids settling in flow. Marine Biology 110, 93103. 
Terlizzi, A., Benedetti-Cecchi, L., Bevilacqua, S., Fraschetti, S., Guidetti, P., Anderson, M.J., 2005. Multivariate and univariate asymmetrical analyses in environmental impact assessment: a case study of Mediterranean subtidal sessile assemblages. Marine Ecology Progress Series 289, 27-42.

Thomalla, F., Vincent, C.E., 2003. Beach response to shore-parallel breakwaters at Sea Palling, Norfolk, UK. Estuarine, Coastal and Shelf Science 56, 203-212.

Thompson, R.C., Crowe, T.P., Hawkins, S.J., 2002. Rocky intertidal communities: past environmental changes, present status and predictions for the next 25 years. Environmental Conservation 29, 168-191.

Underwood, A.J., 1991. Beyond BACI: experimental designs for detecting human environmental impacts on temporal variations in natural populations. Australian Journal of Marine and Freshwater Research 42, 569-587.

Underwood, A.J., 1992. Beyond BACI: the detection of environmental impacts on populations in the real, but variable world. Journal of Experimental Marine Biology and Ecology 161, 145-178.

Underwood, A.J., 1993. The mechanisms of spatially replicated sampling programmes to detect environmental impact in a variable world. Australian Journal of Ecology 18, 99-116.
Underwood, A.J., 1994. On beyond BACI: sampling designs that might reliably detect environmental disturbances. Ecological Applications 4, 3-15.

Underwood, A.J., 1997. Experiments in ecology: their logical design and interpretation using analysis of variance. Cambridge University Press, Cambridge.

Underwood, A.J., Jernakoff, P., 1984. The effects of tidal height, wave-exposure, seasonality and rock-pools on grazing and the distribution of intertidal macroalgae in New SouthWales. Journal of Experimental Marine Biology and Ecology 75, 71-96.

Vadas, R.L., Wright, W.A., Miller, S.L., 1990. Recruitment of Ascophyllum nodosum: wave action as a source of mortality. Marine Ecology Progress Series 61, 263272.

Vaselli, S., Bulleri, F., Benedetti-Cecchi, L., 2008. Hard coastal-defence structures as habitats for native and exotic rocky-bottom species. Marine Environmental Research 66, 395-403.

Zyserman, J.A., Johnson, H.K., Zanuttigh, B., Martinelli, L., 2005. Analysis of far-field erosion induced by low-crested rubble-mound structures. Coastal Engineering 52, 977-994 